\title{
Effect of Long-term Treatment with Somatostatin Analogue (SMS 201-995) on Pituitary Tumor Shrinkage in Acromegaly -Report of Two Cases-
}

\author{
Kazutoshi MUKadA, Tohru UozUMI, Akihiko TAKECHI, Kazunori ARITA, \\ Takashi YANO, Taizo HIROHATA, Jun ONDA and Masahiro OHTA*
}

\author{
Department of Neurosurgery, Hiroshima University School of Medicine, Hiroshima; \\ *Department of Neurosurgery, Ehime Prefectural Central Hospital, Matsuyama
}

\begin{abstract}
The effect of long-term somatostatin analogue (SMS 201-995) treatment in two acromegalic patients is reported. Continuous tumor shrinkage was observed even after 129 and 139 weeks of treatment with $600 \mu \mathrm{g}$ of SMS 201-995 daily. A huge and firm adenoma underwent shrinkage during treatment with SMS 201-995. No serious side effect appeared during 160 weeks of treatment. SMS 201-995 has a longterm tumor shrinkage effect and improves endocrinopathies.
\end{abstract}

Key words: acromegaly, somatostatin analogue, tumor shrinkage, pituitary adenoma

\section{Introduction}

SMS 201-995, a newly developed long-acting somatostatin analogue, strongly inhibits the secretion of growth hormone $(\mathrm{GH}){ }^{2}{ }^{2)}$ Therapeutic use is effective for patients with GH-secreting pituitary adenoma (acromegaly) refractory to surgical or bromocriptine treatment. ${ }^{3,7,11,13,16)}$ SMS 201-995 also causes tumor shrinkage, ${ }^{1,3,4,6-9,12-16)}$ previously observed in a limited number of cases treated with bromocriptine. ${ }^{(0)}$ It therefore has an important future role in the treatment of acromegaly. However, few clinical investigations have evaluated tumor shrinkage during long-term treatment. ${ }^{1)}$ We report our clinical findings, especially tumor shrinkage, in two patients with acromegaly treated for over 3 years with SMS 201-995.

\section{Case Reports}

Case 1: A 36-year-old male was admitted with progressive acral enlargement and overt diabetes mellitus on February 1, 1982. He demonstrated typical signs of active acromegaly, such as acromegalic countenance, acral enlargement, and excessive sweating. Neurological examination found bitemporal visual field defects. Computed tomographic (CT) scans disclosed a huge invasive tumor with suprasellar, sphenoid, and cavernous sinus extension. Transsphenoidal surgery on March 8, 1982 achieved only partial tumor removal from the sphenoid sinus, because the tumor was firm and bleeding heavily. The histological diagnosis of the tumor specimen was mixed (acidophilic and chromophobic) pituitary adenoma. Postoperatively, the visual disturbance improved, but the endocrinological symptoms remained unchanged. 20 $\mathrm{mg}$ of bromocriptine was therefore administered dai$\mathrm{ly}$, but was ineffective. He continued to have high blood GH levels $(38-160 \mathrm{ng} / \mathrm{ml})$. Other clinical data are shown in Table 1.

Subcutaneous SMS 201-995 injection ( $50 \mu$ g every 8 hours) was begun on November 26,1987 . The dose was subsequently increased to $200 \mu$ g every 8 hours. However, the blood GH levels rose markedly. The somatomedin-C levels also increased, despite falling

Received March 6, 1991; Accepted September 12, 1991

Author's present address: K. Mukada, M.D., Division of Neurosurgery, Itsukaichi Memorial Hospital, Hiroshima, Japan. 
Table 1 Endocrinological data before treatment with SMS 201-995

\begin{tabular}{|c|c|c|c|c|}
\hline & \multicolumn{2}{|c|}{ Case 1} & \multicolumn{2}{|c|}{ Case 2} \\
\hline & Basal & $\begin{array}{l}\text { Peak or } \\
\text { nadir }\end{array}$ & Basal & $\begin{array}{l}\text { Peak or } \\
\text { nadir }\end{array}$ \\
\hline \multicolumn{5}{|l|}{$\begin{array}{l}\text { Basal GH level }(\mathrm{ng} / \mathrm{ml}) \text { and } \\
\text { response to: }\end{array}$} \\
\hline glucose $(75 \mathrm{gm})$ & 56.0 & 61.0 & 43.0 & 83.0 \\
\hline TRH (0.5 mg) & 65.0 & 140.0 & 27.8 & 76.3 \\
\hline LHRH (0.1 mg) & 63.0 & 64.0 & 50.0 & 113.1 \\
\hline insulin $(0.1 \mathrm{U} / \mathrm{kg})$ & \multicolumn{2}{|c|}{ not performed } & 26.5 & 86.0 \\
\hline bromocriptine $(2.5 \mathrm{mg})$ & 57.9 & 30.8 & 36.0 & 35.0 \\
\hline SMS 201-995 (50 $\mu \mathrm{g})$ & 66.0 & 9.0 & 23.0 & 2.0 \\
\hline Plasma somatomedin-C $(\mathrm{U} / \mathrm{ml})$ & 7.80 & & 1.95 & \\
\hline
\end{tabular}

LHRH: luteinizing hormone-releasing hormone, TRH: thyroid hormone-releasing hormone.

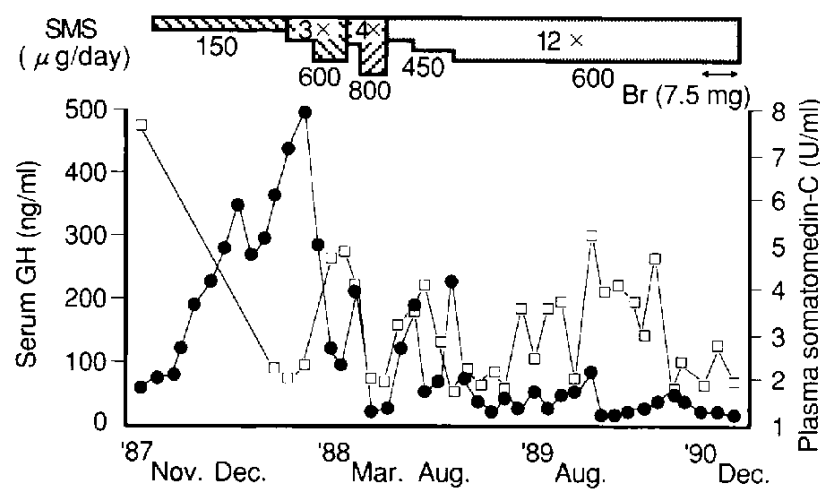

Fig. 1 Case 1. Basal GH (•) and somatomedin-C levels ( $\square$ ) during SMS 201-995 treatment. Br: bromocriptine.

during the initial stage of treatment (Fig. 1). Different dose regimens were tried, before $50 \mu \mathrm{g}$ every $\mathbf{2}$ hours via infusion pump was finally chosen for the maintenance dosage. Details of this pro- cedure were reported previously. ${ }^{15)}$ CT scans showed that the greatest tumor dimension had shrunk by $16 \%$, from 55 to $46 \mathrm{~mm}, 29$ weeks after beginning SMS 201-995 treatment (Fig. 2A, B). Magnetic resonance (MR) images showed the shrinkage to be $27 \%$, to $40 \mathrm{~mm}$, in the 129 th week (Fig. 2C). SMS 201-995 treatment also improved the excessive sweating and arrested the progress of acral enlargement.

Bromocriptine was simultaneously administered from the 132nd week in an attempt to obtain a better clinical effect. The blood $\mathrm{GH}$ and somatomedin$\mathrm{C}$ levels had stabilized at $20-30 \mathrm{ng} / \mathrm{ml}$ and $2-3 \mathrm{U} /$ $\mathrm{ml}$, respectively, in the 165th week (Fig. 1). No side effects due to SMS 201-995 have been observed and the insulin dosage administered for diabetes mellitus has remained unchanged.

Case 2: A 36-year-old female was admitted with progressive acral enlargement, amenorrhea, and visual disturbance on October 15, 1984. She had typical acromegalic features and right homonymous hemianopsia. CT scans showed a large tumor with suprasellar extension. Transsphenoidal surgery on October 22, 1984 achieved subtotal tumor removal, and failed to normalize blood GH levels, although the right homonymous hemianopsia disappeared completely. The histological diagnosis of the tumor specimen was acidophilic pituitary adenoma. Reoperation on September 2, 1985 also resulted in subtotal tumor removal, and failed to reduce the blood GH levels. $30 \mathrm{mg}$ of bromocriptine was then administered daily, but without effect. Other clinical data are shown in Table 1 .

Subcutaneous SMS 201-995 injection (50 $\mu \mathrm{g}$ every 8 hours) was begun on January 30, 1988. The dose was subsequently increased to $200 \mu \mathrm{g}$ every 8 hours. The blood $\mathrm{GH}$ and somatomedin-C levels fell to within the normal ranges (Fig. 3), and the clinical symptoms improved. CT scans before treatment re-

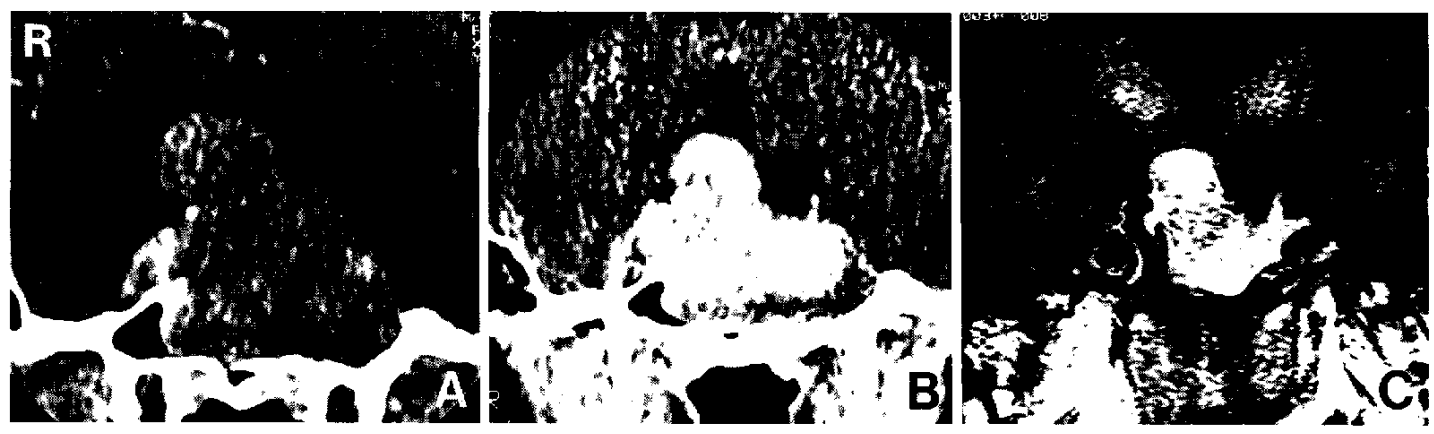

Fig. 2 Case 1. Postcontrast coronal CT scans (A, B) and MR image (C) before and during SMS 201-995 treatment. A: before treatment, B: the 29 th week, C: the 129 th week. 


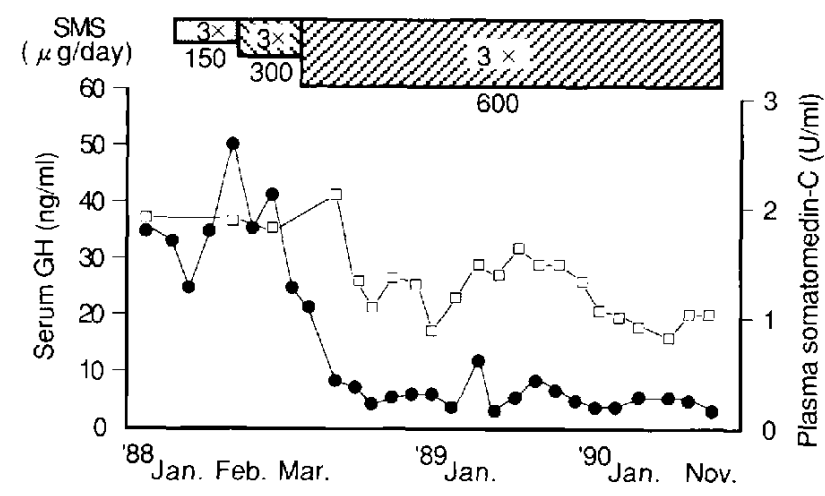

Fig. 3 Case 2. Basal $\mathrm{GH}(\bullet)$ and somatomedin-C levels ( $\square$ ) during SMS 201-995 treatment.
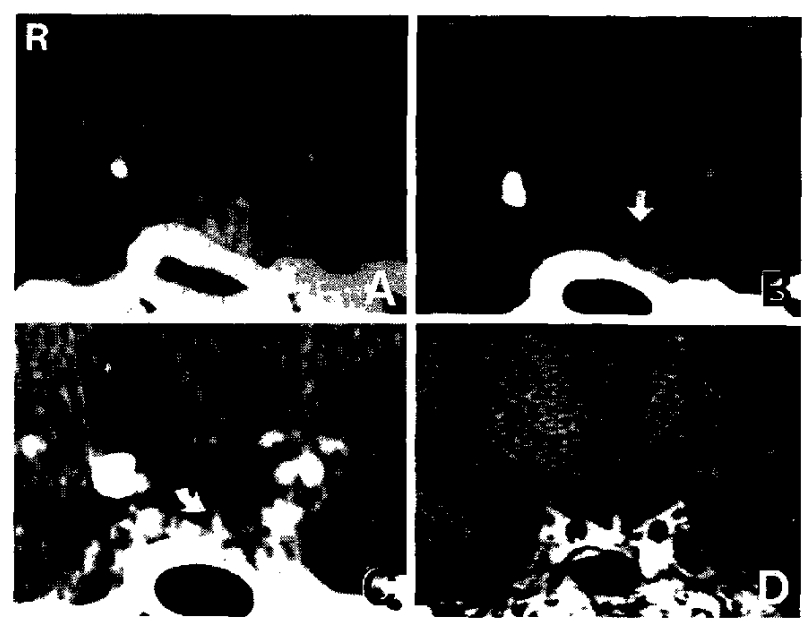

Fig. 4 Case 2. Postcontrast coronal CT scans (A-C) and MR image (D) before and during SMS 201995 treatment. A: Before treatment. B: In the 27th week, decrease in the left pituitary volume (arrow) is observed. C: In the $96 \mathrm{th}$ week, further decrease in the left pituitary volume and shift of the pituitary staik to the left (arrow) are observed. D: In the 139th week, persistent tumor-shrinking effect is observed.

vealed small tumor fragments in the left half of the sella turcica (Fig. 4A). In the 27th week, the volume of the sellar contents had decreased (Fig. 4B). A further decrease was seen in the 96th week, especially in the left half of the sella turcica (Fig. 4C). CT scans also showed a shift of the pituitary stalk to the left, an indirect sign of tumor shrinkage. MR images in the 139th week showed prolonged shrinkage of the tumor (Fig. 4D).

The satisfactory effect was maintained in the 156th week (Fig. 3). No side effects, other than transient diarrhea, have been observed.

\section{Discussion}

Our two acromegalic patients received SMS 201-995 for more than 3 years, the longest treatment durations so far reported (Table 2). In addition, we were able to monitor the pituitary tumors radiologically. In Case 1, the greatest tumor dimension decreased by 16 and $27 \%$ after SMS 201-995 treatment for 29 and 129 weeks, respectively. This was a fibrous and firm adenoma, which was usually difficult to remove, but the tumor-shrinking effect definitely persisted for a long period after the start of SMS 201-995 treatment. In Case 2 as well, the tumor-shrinking effect persisted after the 27 th week of treatment.

Barkan et al." administered $150-1000 \mu \mathrm{g}$ of SMS 201-995 daily to 10 untreated cases of acromegaly, all with invasive adenoma, for 3-30 weeks. CT scans showed a $20-54 \%$ decrease in tumor volume in all cases. The maximum tumor-shrinking effect appeared within 8-12 weeks. Sassolas et al. ${ }^{12)}$ monitored 38 cases by CT scanning during SMS 201 995 treatment, finding that tumor shrinkage did not persist (except in 3 cases) after 6 months. In both our cases, the tumor shrinkage persisted after the period of maximum effect reported by these authors.

No detailed and systematic investigation of the tumor-shrinking effect of SMS 201-995 is available for large numbers of cases. Our cases presented no unusual characteristics in their clinical courses before drug treatment, endocrinological data, or histological findings. Case 1 was unusual, in that resistance to lowering of blood $\mathrm{GH}$ levels by SMS 201-995 was found during the early stage of treatment. ${ }^{(5)}$ However, there is no clear relationship between this finding and the persistent tumor shrinkage.

Morphometric study suggests that tumor shrinkage with SMS 201-995 is caused by a decrease in both cytoplasmic and nuclear volumes, suggesting endogenous somatostatin influences these changes in the tumor ultrastructure. ${ }^{1)}$ Therefore, evaluation of the tumor-shrinking effect of SMS 201-995 requires further investigation of endogenous somatostatin and intrinsic hypothalamic hormones, including GH-releasing hormone.

In Japan, SMS 201-995 treatment has been mainly used in acromegalic patients for whom surgical, bromocriptine, and/or radiation therapy were ineffective. ${ }^{13)}$ However, SMS 201-995 has caused tumor shrinkage in a number of cases of macroadenoma,,$^{1,4,6,12,15)}$ so preoperative administration should be 
Table 2 Review of SMS 201-995 effect on pituitary tumor shrinkage

\begin{tabular}{|c|c|c|c|c|c|}
\hline Author (Year) & $\begin{array}{l}\text { No. of patients } \\
\text { with tumor } \\
\text { shrinkage }\end{array}$ & $\begin{array}{c}\text { Dose of } \\
\text { SMS 201-995 } \\
(\mu \mathrm{g} / \text { day })\end{array}$ & $\begin{array}{l}\text { Length of } \\
\text { treatment } \\
\text { (wks) }\end{array}$ & $\begin{array}{l}\text { Degree of } \\
\text { tumor shrinkage }\end{array}$ & Remarks \\
\hline $\begin{array}{l}\text { Lamberts et al. } \\
(1985)^{9)}\end{array}$ & $3 / 4 \quad(75 \%)$ & $100-300$ & $8-24$ & slight & \\
\hline $\begin{array}{l}\text { Tolis et al. } \\
\qquad(1986)^{16)}\end{array}$ & $3 / 9 \quad(33 \%)$ & $50-200$ & $6-20$ & - & \\
\hline $\begin{array}{c}\text { Chiodini et al. } \\
(1987)^{3)}\end{array}$ & $3 / 10 \quad(30 \%)$ & $100-300$ & $30-47$ & $30-45 \%$ & \\
\hline $\begin{array}{l}\text { Sandler et al. } \\
\quad(1987)^{11)}\end{array}$ & $0 / 8$ & 300 & $12-60$ & - & \\
\hline $\begin{array}{l}\text { Spinas et al. } \\
(1987)^{14 !}\end{array}$ & $1 / 5(20 \%)$ & 300 & $1-4$ & $17 \%$ & preoperative administration \\
\hline $\begin{array}{l}\text { Barkan et al. } \\
(1988)^{1)}\end{array}$ & $10 / 10(100 \%)$ & $150-1000$ & $3-30$ & $20-54 \%$ & $\begin{array}{l}\text { de novo patients with grade } \\
\text { III or IV tumors }\end{array}$ \\
\hline $\begin{array}{l}\text { Cozzi et al. } \\
(1988)^{4}\end{array}$ & $12 / 21 \quad(57 \%)$ & $100-1500$ & $3-35$ & $15-90 \%$ & macroadenoma \\
\hline $\begin{array}{l}\text { Horikawa et al. } \\
(1988)^{7)}\end{array}$ & $7 / 9 \quad(78 \%)$ & $300-800$ & $3-38$ & slight $-44 \%$ & \\
\hline $\begin{array}{c}\text { Shimatsu et al. } \\
(1989)^{13)}\end{array}$ & $11 / 40 \quad(28 \%)$ & $100-1500$ & $2-114$ & - & multicenter trial in Japan \\
\hline $\begin{array}{l}\text { Sassolas et al. } \\
\quad(1990)^{12)}\end{array}$ & $11 / 23 \quad(48 \%)$ & $300-1500$ & 24 & $\begin{array}{l}6 \text { cases: } \gtrsim_{50} 50 \% \\
5 \text { cases: } 20-50 \%\end{array}$ & $\begin{array}{l}\text { large tumors or tumor remnants } \\
\quad \text { (largest diameter: } \geqq 20 \mathrm{~mm} \text { ) }\end{array}$ \\
\hline Present report & $2 / 2(100 \%)$ & 600 & $\begin{array}{l}\text { Case 1: } 165 \\
\text { Case 2: } 156\end{array}$ & $\begin{array}{l}27 \% \\
\text { slight }\end{array}$ & fibrous adenoma \\
\hline
\end{tabular}

positively considered for untreated acromegalic patients to improve surgical results. ${ }^{1,14)}$ Pretreatment with bromocriptine in patients with prolactinoma causes useful tumor shrinkage. ${ }^{5,17}$ Barkan et al." reported better remission rates for acromegalic patients receiving SMS 201-995 for 3-30 weeks before surgery, compared with acromegalic patients with similarly sized tumors not receiving the drug, and operated on by the same surgeon. Spinas et al. ${ }^{14}$ reported that the tumors in five patients with untreated acromegaly receiving $300 \mu \mathrm{g}$ of SMS 201995 daily for 1-4 weeks were subsequently extirpated easily because of the soft tumor tissue and well-defined boundary from normal pituitary tissue. Horikawa et $a .^{7}{ }^{7}$ also reported that treatment with SMS 201-995 before operation produced satisfactory surgical results.

Preoperative SMS 201-995 treatment may therefore significantly improve surgical results, especially in patients with macroadenoma. However, wider use of SMS 201-995 for endocrinological and tumor-shrinking treatment requires more detailed and systematic investigation of the drug dosage, and the relationship between treatment duration and tumor shrinkage, surgical results, and histology of the tumor. Preoperative treatment is often discouraged by the unsettled problem of treatment duration. The present work and Barkan et al. ${ }^{1)}$ suggest that this is at least $8-12$ weeks. If CT scans or MR images show the tumor to have shrunk, endocrinological abnormalities have improved, and no immediate surgical decompression is necessary, then further treatment for around 30 weeks to observe tumor shrinkage before operation can be recommended.

Our two cases began treatment with SMS 201-995 approximately 3 years ago, and continue with the drug. No escape phenomena have been observed, and normalized blood $\mathrm{GH}$ and somatomedin-C levels persist in one. In addition, no side effects requiring discontinuance of treatment were experienced.

The present study shows that SMS 201-995 can cause tumor shrinkage for a period longer than that previously reported, and can maintain endocrinological improvement. The incidence of side effects is extremely low, even with long-term treatment. Further detailed investigation is necessary on the effect of SMS 201-995 as a pretreatment drug to improve surgical results, and the effective dosage for tumor shrinkage.

\section{Acknowledgment}

The present study with SMS 201-995 was started with patient consent after a full explanation of the nature 
and purpose of the study.

The authors are greatly indebted to Sandoz Pharmaceutical Co. (Tokyo) for supplying somatostatin analogue, SMS 201-995.

\section{References}

1) Barkan AL, Lloyd RV, Chandler WF, Hatfield MK, Gebarski SS, Kelch RP, Beitins IZ: Preoperative treatment of acromegaly with long-acting somatostatin analog SMS 201-995: Shrinkage of invasive pituitary macroadenomas and improved surgical remission rate. $J$ Clin Endocrinol Metab 67: 10401048,1988

2) Bauer $W$, Briner $U$, Doepfner $W$, Haller $R$, Huguenin R, Marbach P, Petcher TJ, Pless J: SMS 201-995: A very potent and selective octapeptide analogue of somatostatin with prolonged action. Life Sci 31: 1133-1140, 1982

3) Chiodini PG, Cozzi R, Dallabonzana D, Oppizzi G, Verde G, Petroncini M, Liuzzi A, del Pozo E: Medical treatment of acromegaly with SMS 201-995, a somatostatin analogue: A comparison with bromocriptine. J Clin Endocrinol Metab 64: 447453, 1987

4) Cozzi R, Chiodini PG, Boccardi E, Dallabonzana D, Oppizzi G, De Palo C, Piolini M, Liuzzi A: Tumorsize reduction of $\mathrm{GH}$ secreting adenomas during long-term treatment of acromegaly with SMS 201-995 (Sandostatin), in: 8th International Congress of Endocrinology (Abstr). 1988, p 244

5) Fahlbusch R, Buchfelder M, Schrell U: Short-term preoperative treatment of macroprolactinomas by dopamine agonists. $J$ Neurosurg 67: 807-815, 1987

6) Goto $T$, Natori $S$, Suematsu $E$, Higuchi $K$, Takayanagi R, Haji M, Ohashi M, Nawata S: A case of acromegaly in which pituitary tumor shrinkage could be obtained by treatment with SMS 201-995 (somatostatin analogue). Rinsho To Kenkyu 66: 2545-2550, 1989 (in Japanese)

7) Horikawa R, Takano K, Hizuka N, Asakawa K, Sukegawa I, Hirose N, Horiba N, Kasono K, Masuda A, Ohba Y, Nakagami Y, Tsushima T, Shizume K: Treatment of acromegaly with long acting somatostatin analogue SMS 201-995. Endocrinol Jpn 35: $741-751,1988$

8) Jackson IMD, Barnard LB, Lamberton P: Role of a long-acting somatostatin analogue (SMS 201-995) in the treatment of acromegaly. Am J Med 81 [Suppl]:
$94-101,1986$

9) Lamberts SWJ, Uitterlinden P, Verschoor L, van Dongen KJ, del Pozo E: Long-term treatment of acromegaly with the somatostatin analogue SMS 201995. N Engl J Med 313: 1576-1580, 1985

10) Oppizzi G, Liuzzi A, Chiodini P, Dallabonzana D, Spelta B, Silvestrini F, Borghi G, Tonon C: Dopaminergic treatment of acromegaly: Different effects on hormone secretion and tumor size. $J$ Clin Endocrinol Metab 58: 988-992, 1984

11) Sandler LM, Burrin JM, Williams G, Joplin GF, Carr DH, Bloom SR: Effective long-term treatment of acromegaly with a long-acting somatostatin analogue (SMS 201-995). Clin Endocrinol (Oxf) 26: $85-95,1987$

12) Sassolas G, Harris AG, James-Deidier A: Long term effect of incremental doses of the somatostatin analog SMS 201-995 in 58 acromegalic patients. $I$ Clin Endocrinol Metab 71: 391-397, 1990

13) Shimatsu A, Imura $H$, Irie $M$, Nakagawa $S$, Goto $Y$, Shimizu N, Takeda R, Kato Y, Saito S, Ibayashi H, Nawata S, Shizume K, Uozumi T: A multicenter clinical trial of SMS 201-995 (octreotide acetate) in acromegaly and gigantism. Folia Endocrinol 65: 640652,1989 (in Japanese)

14) Spinas GA, Zapf J, Landolt AM, Stuckmann G, Froesch ER: Pre-operative treatment of 5 acromegalics with a somatostatin analogue: Endocrine and clinical observations. Acta Endocrinol (Copenh) 114: 249-256, 1987

15) Takechi A, Mukada K, Yano T, Hirohata T, Onda J, Uozumi T: Growth hormone-secreting huge pituitary adenoma resistant to the treatment with somatostatin analogue SMS 201-995. Case report. Horumon To Rinsho 38 [Suppl]: 88-92, 1990 (in Japanese)

16) Tolis G, Yotis A, del Pozo E, Pitoulis S: Therapeutic efficacy of a somatostatin analogue (SMS 201-995) in active acromegaly. J Neurosurg 65: 37-40, 1986

17) Weiss MH, Wycoff RR, Yadley R, Gott P, Feldon S: Bromocriptine treatment of prolactin-secreting tumors: Surgical implications. Neurosurgery 12: 640642,1983

Address reprint requests to: K. Mukada, M.D., Division of Neurosurgery, Itsukaichi Memorial Hospital, 1-95 Kurashige, Saeki-ku, Hiroshima 731-51, Japan. 